\title{
THE FUNCTION OF THE KIDNEYS IN PATIENTS SUFFERING FROM CHRONIC CARDIAC DISEASE WITHOUT SIGNS OF HEART. FAILURE
}

\author{
By HAROLD J. STEWART AND JOHN F. McINTOSH
}

(From the Hospital of The Rockefeller Institute for Medical Research, New York)

(Received for publication July 30, 1928)

This study is concerned with the function of the kidneys in patients suffering from chronic heart disease during periods when they show no signs of heart failure.

Studies of renal function during attacks of heart failure have of course been numerous. With the introduction of each new test of renal function its usefulness in cardiac patients has been explored, often however without attempting to correlate it with other tests already in use. Following the introduction of phenolsulphonephthalein by Rowntree and Geraghty (1912), investigations by Rowntree, Fitz and Geraghty (1913), Rowntree and Fitz (1913), Rowntree, Marshall and Baetjer (1915), Frothingham and Smillie (1914) and Agnew (1915) were published. The outcome of all these studies is the same, namely, that excretion of this substance is much reduced, if there is a marked degree of chronic passive congestion; with restoration of compensation excretion again becomes normal. McLean (1915) studied these cases from a slightly different point of view. Instead of measuring the excretion of a substance introduced from without, he estimated a natural function, in this case urea excretion and found that the index of ureas excretion was low during decompensation, but increased as the signs of heart failure disappeared. As an indication of the state of the circulation, it ran parallel to the test of Rowntree and Geraghty (1912). In all these investigations the emphasis has been placed more or less upon the state of the kidneys as a phase of heart failure. Important though it is to be aware of this matter, it is equally, perhaps more important to know whether the kidneys are essentially damaged or whether their behavior merely reflects the state of the whole organism, caught as it is, in the process of heart failure. For this reason we have examined the 
condition of the kidneys in cardiac patients after having returned to a state of compensation and in doing so have correlated the tests which are most frequently used.

In patients recently recovered from attacks of heart failure, tests were made a few days before sitting up. The patients were taking ward diet, free of salt except that used in cooking. The tests selected were: (1) the urea concentration index (the Van Slyke index) described by Van Slyke, Linder, Hiller, Leiter and McIntosh (1926); (2) the phenolsulphonephthalein test; (3) the concentration test, and (4) the dilution or water test.

1. The significance of ascertaining the concentrating power of the kidneys for urea under standard conditions is stated by McIntosh and Reimann (1926) to be: "The significance of the urea concentration index may be described by stating that it represents the number of times the kidneys concentrate urea in excreting it from the blood into the urine, when the urine volume output is at the average normal rate of $1 \mathrm{cc}$. per minute or $1 \mathrm{cc}$. per hour per kilo body weight." The index may also be regarded as representing the number of cubic centimeters of blood cleared of urea by the kidneys when urine is being excreted at the rate of 1 cubic centimeter per minute. Values of 35 to 80 for the index are regarded as normal.

2. Phenolsulphonephthalein $1 \mathrm{cc}$. was injected intravenously. Urine specimens were collected at the end of 1 and of 2 hours. The amount of the dye excreted was then estimated. The dye was given at the end of the urea concentration test. Excretion of 55 per cent or more of the dye in $\mathbf{2}$ hours was considered to be normal.

3. The aim of the concentration test is to study the behavior of the kidneys under mild stress. In 1914 Hedinger and Schlayer (1914) introduced a test diet for cases of nephritis which was further elaborated by Mosenthal (1915) in 1915. The test as we have used it was devised in this hospital by Lundsgaard. The patients are given 3 dry meals. Each meal consists of bread (toasted) 65 grams, butter 15 grams, eggs (scrambled) 100 grams, cream cheese 25 grams, and jam or jelly 15 grams to 20 grams. The caloric value of this meal is 600 calories, a total of 1800 calories. No water is given from midnight of the day preceding the test until its end. On the morning of the test the patient voids at 6 a.m. This specimen is discarded. He voids again at 7 a.m., this specimen being saved. The dry meals are given at 7.30, 10.00 and 11.40 a.m. The patient voids at 9 and at 11 a.m., at 1 and at 3 p.m.; each specimen is saved separately. The test ends after the specimen is collected at 3 p.m. The amount and specific gravity of each specimen are estimated. In normal individuals the specific gravity rises to 1.030 during this test. We have however arbitrarily decided to regard 1.025 to 1.030 as within the normal limits for the purposes of this study.

4. Dilution or water tests have been described by Koranyi and his pupils 
Kövesi and Roth-Schulz (1904), (1900), by Strauss (1902), by Grünwald (1907), and by Volhard (1910). The test gives information both about the rate of water excretion and the diluting ability of the kidneys. The test is applied as follows. It is carried out in the morning. The patient receives no fluid after midnight. A specimen collected at 6 a.m. is discarded. After voiding at 7 a.m. (this specimen is saved) the patient drinks water $1000 \mathrm{cc}$. No more fluid and no food are given until after the test is ended at 11 a.m. Specimens are collected at 8 , at 9 , at 10 and at 11 a.m. and are saved separately. They are measured and the specific gravity of each is estimated. Normal individuals excrete all or nearly all of the $1000 \mathrm{cc}$. of water ingested within the 4 hours of the test; the specific gravity falls to 1.001 . For the purposes of this investigation we have regarded the function to be normal if $750 \mathrm{cc}$. or more of the water were excreted in 4 hours and the specific gravity in any specimen fell to 1.005 or lower.

The dilution test is to some extent dependent upon the rate of absorption of the water ingested from the stomach and intestines. This will probably vary from one normal individual to another; it is sufficiently constant however so that normal individuals may be expected to excrete within 4 hours nearly all of the 1000 cc. of water given in the test. Absorption will be influenced also no doubt by the state of congestion of the abdominal viscera. Only those patients were subjected to this test who had completely recovered from attacks of heart failure and who were in a good state. They were on a fixed daily fluid intake and were in water equilibrium at that level. Cardiac patients have suffered no inconvenience from taking this amount of water. To be certain to avoid damage, the fluid intake was maintained at the end of the test at as low a level as possible for the remainder of the day; by so doing the total fluid intake for the 24 hours did not surpass the usual daily allowance.

The four tests were usually made on three successive days. On the first day the urea concentration index was first estimated. This was followed by the phenolsulphonephthalein test. The concentration and dilution tests were carried out on the second and third days respectively.

Specimens were tested for the presence of albumin. Sediments obtained on centrifugalization were examined under the microscope.

We have attempted to correlate the response of the kidneys to these tests with (1) the age of the patient, (2) the etiology of the cardiac disease, (3) the type of heart failure (for example congestive or dyspneic), (4) the number of attacks of heart failure the patient has sustained, (5) the length of time since the diagnosis of heart disease was made, and (5a) the length of time since the onset of the first attack of heart failure. Finally, (6) we wished to estimate the relative value of these tests in such patients.

Renal function in patients with compensated hearts. The excretion of 


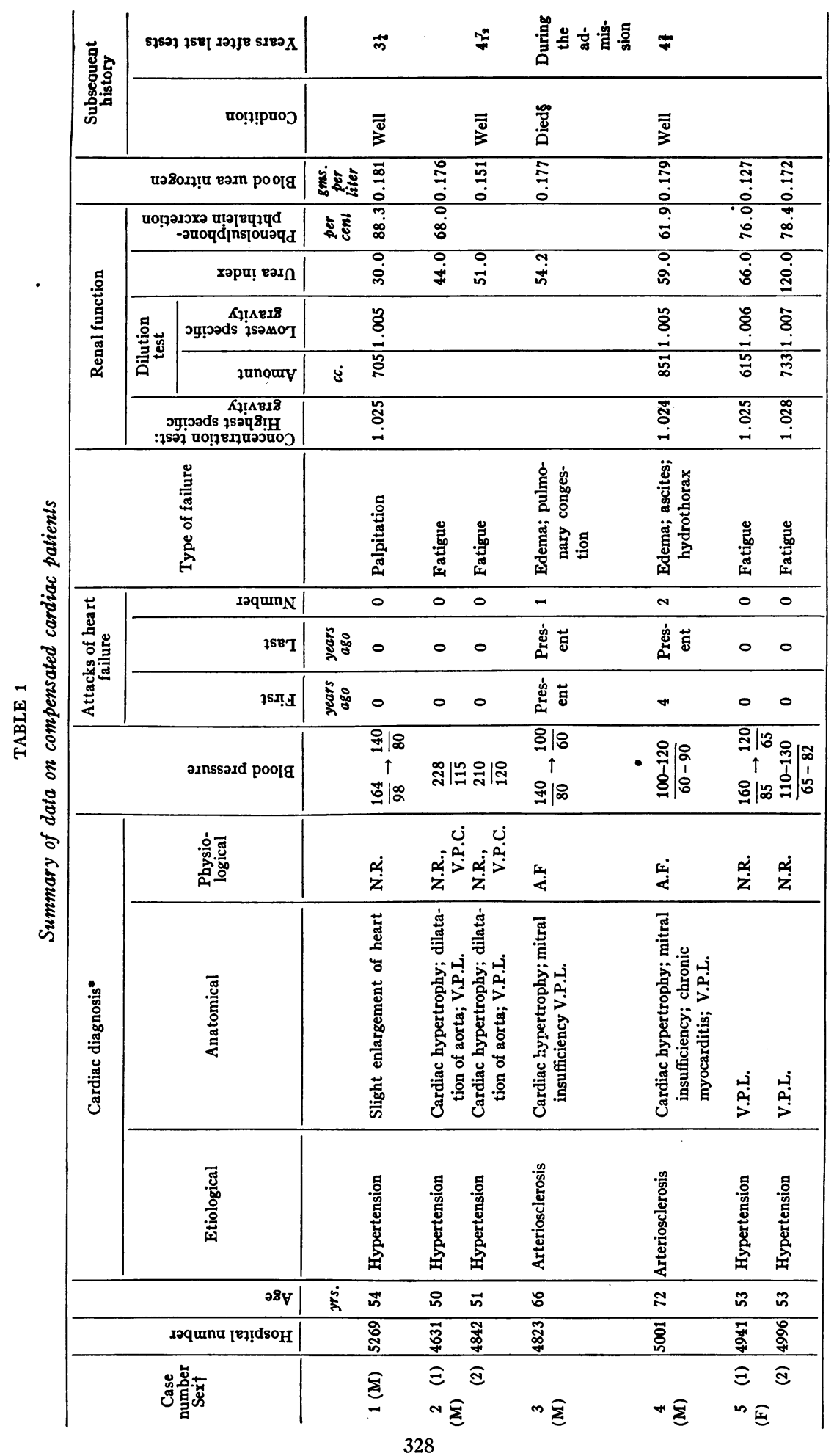




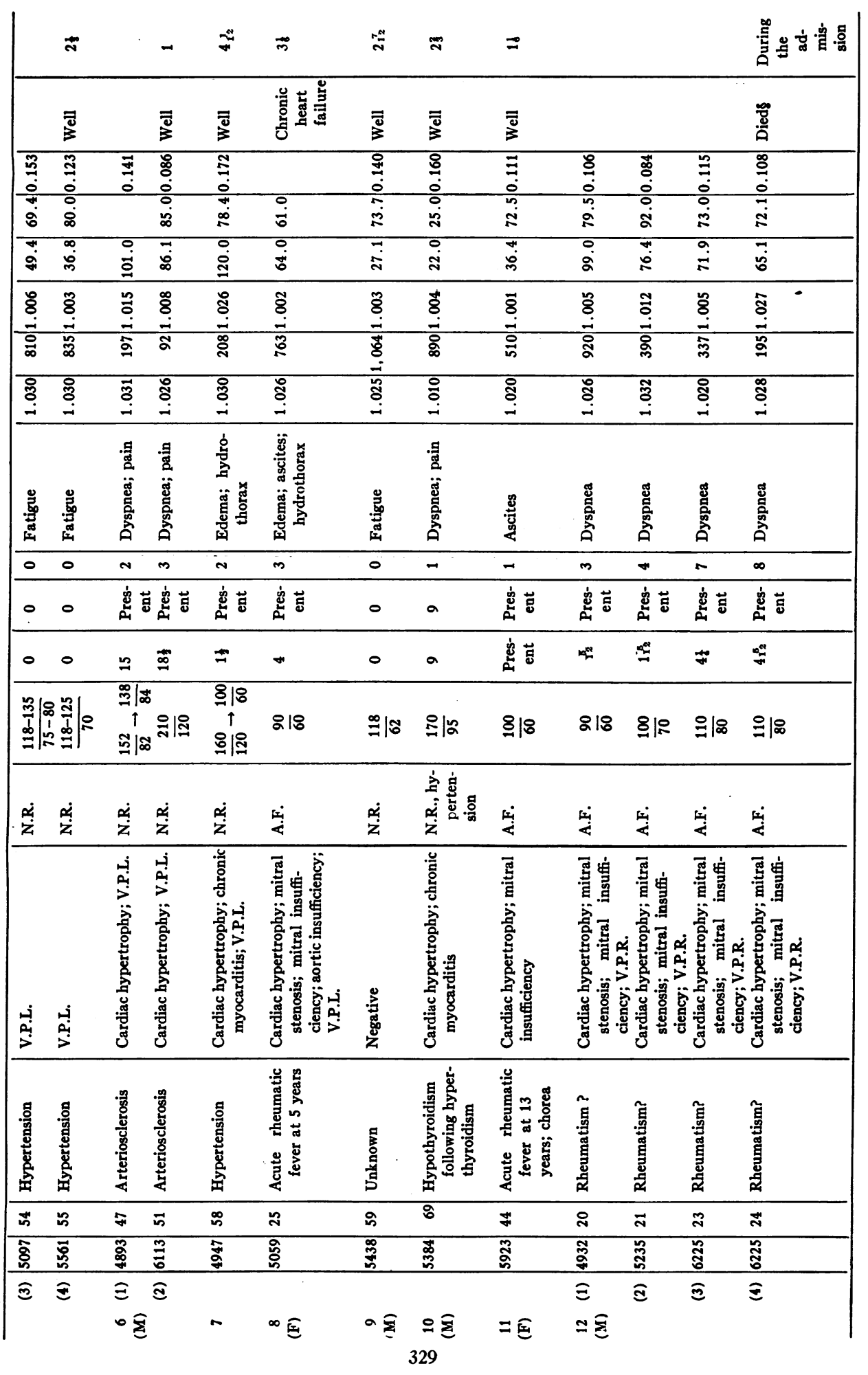




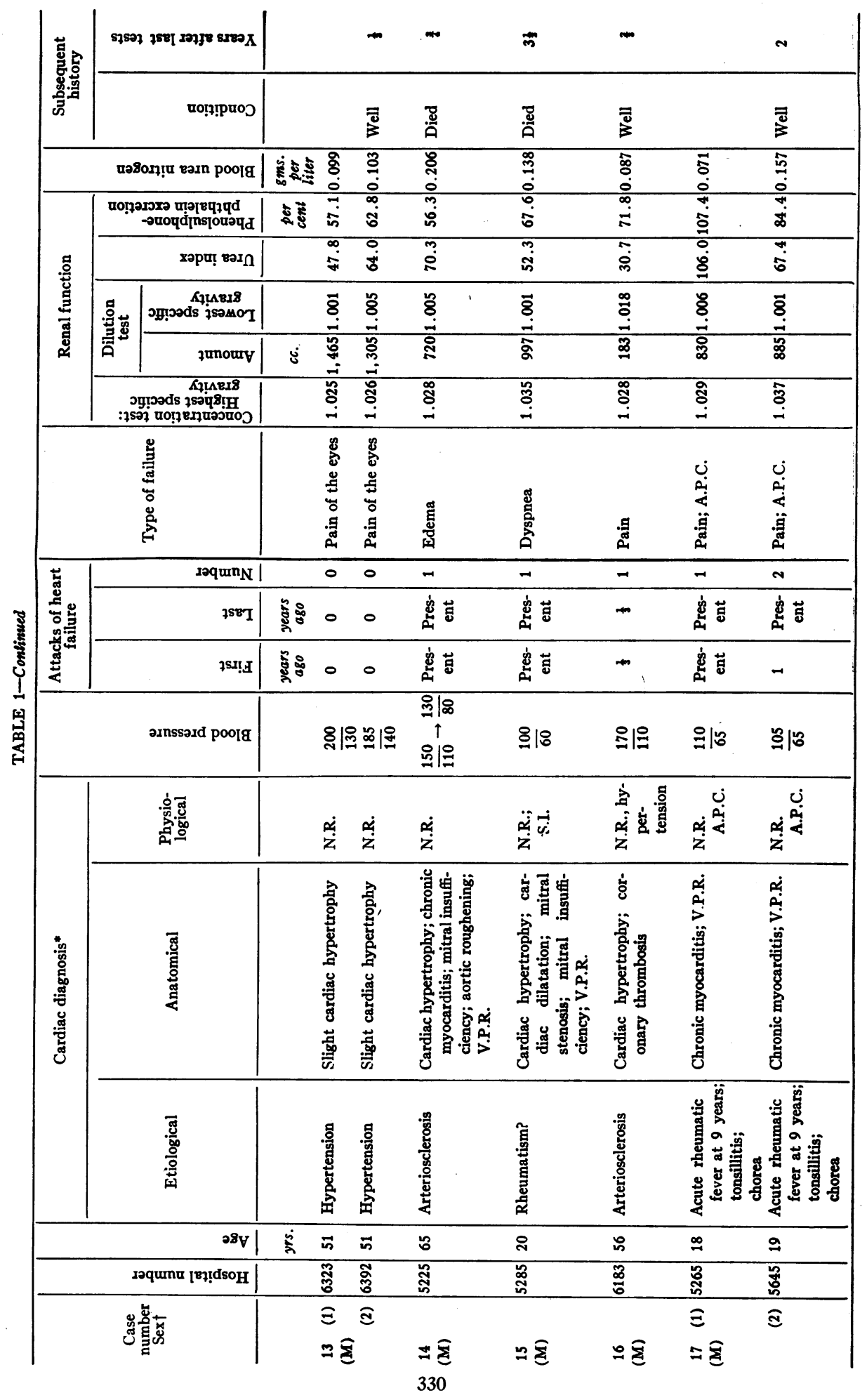




\begin{tabular}{|c|c|c|c|c|c|c|c|}
\hline$\approx$ & & 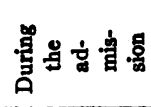 & - & 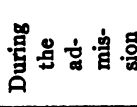 & & - & $\infty$ \\
\hline $\bar{\Xi}$ & & 唯 & 泡 & 㮫 & & 尹̈ & $\bar{\Xi}$ \\
\hline 兽 & $\begin{array}{l}8 \\
0 \\
0 \\
\end{array}$ & $\begin{array}{l}\frac{7}{1} \\
\vdots \\
0 \\
\infty\end{array}$ & 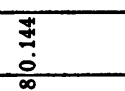 & : & 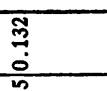 & & 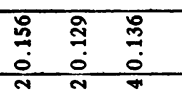 \\
\hline 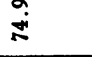 & $\infty$ & $\stackrel{\infty}{\infty}$ & نे & 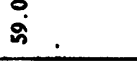 & 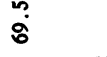 & : & ڤั \\
\hline$\stackrel{4}{\pi}$ & $\stackrel{\circ}{i}$ & ij & 亦 & $\begin{array}{l}0 \\
i \\
i\end{array}$ & i্ & 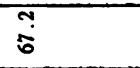 & 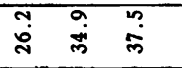 \\
\hline ६̊ & \% & 8 & & & 8 & 8 & 岁 $\overline{8} \quad \overline{8}$ \\
\hline 总 & 亯 & बूँ & & & 8 & 商 & 产 \\
\hline 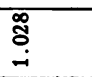 & 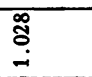 & స్ & & & 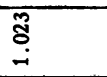 & $\underset{-}{\tilde{I}}$ & 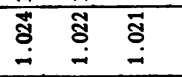 \\
\hline 营 & 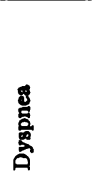 & 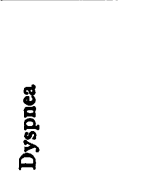 & 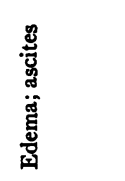 & 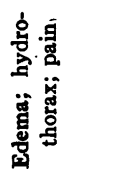 & 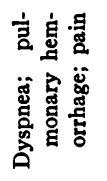 & 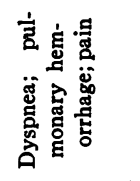 & 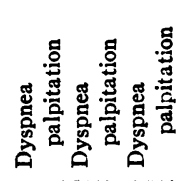 \\
\hline 0 & - & $\infty$ & - & $N$ & 0 & - & 000 \\
\hline$\circ$ & 安 & 悹范 & 密萿 & 离 & 离范 & 宙范 & 000 \\
\hline$\circ$ & 离芩 & $\bar{m}$ & 密 & + & \pm & $\simeq$ & 00 \\
\hline 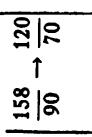 & $\stackrel{g}{\exists}$ & $\$$ & $\begin{array}{l}218 \\
1 \\
018 \\
0\end{array}$ & ఫ̊ & 8) & ఫ్1/8 & 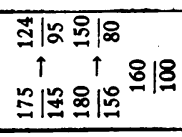 \\
\hline 离 & 车 & 安 & 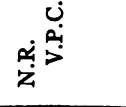 & 我 & 安 & 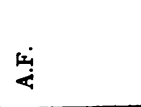 & 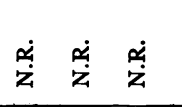 \\
\hline 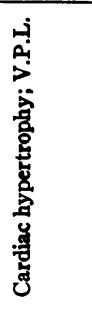 & 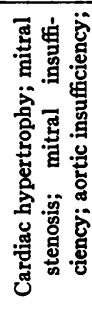 & 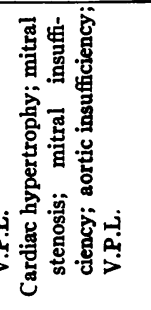 & 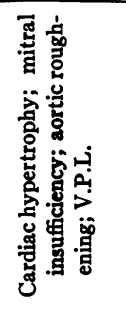 & 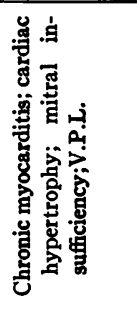 & 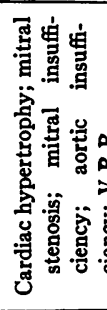 & 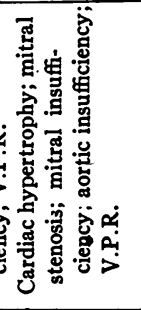 & 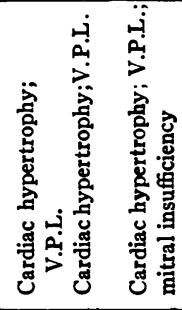 \\
\hline 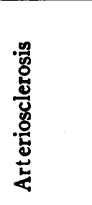 & 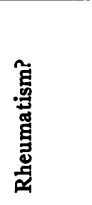 & 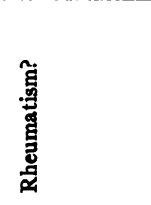 & 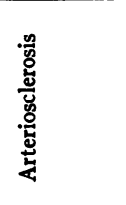 & 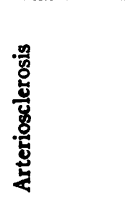 & 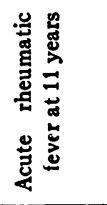 & 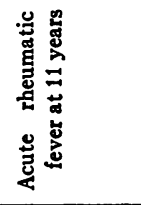 & 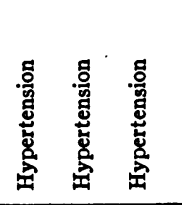 \\
\hline$\tilde{6}$ & 8 & $\approx$ & 80 & 5 & $\not$ & $\stackrel{\overbrace{}}{\circ}$ & $\bar{n}$ \\
\hline$\sum_{\substack{\infty \\
n}}^{\infty}$ & : & 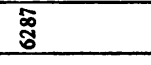 & 高 & 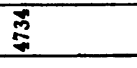 & 总 & 8 & $\begin{array}{lll}\bar{g} & \overrightarrow{\mathrm{B}} \\
\end{array}$ \\
\hline$\infty \bar{\varepsilon}$ & $\begin{array}{l}\bar{\Xi} \\
a \bar{g}\end{array}$ & $\Xi$ & 우토 & $\overline{\bar{\varepsilon}}$ & $\begin{array}{l}\bar{\Xi} \\
\approx \bar{\xi}\end{array}$ & $\widehat{\S}$ & 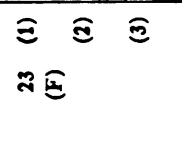 \\
\hline
\end{tabular}




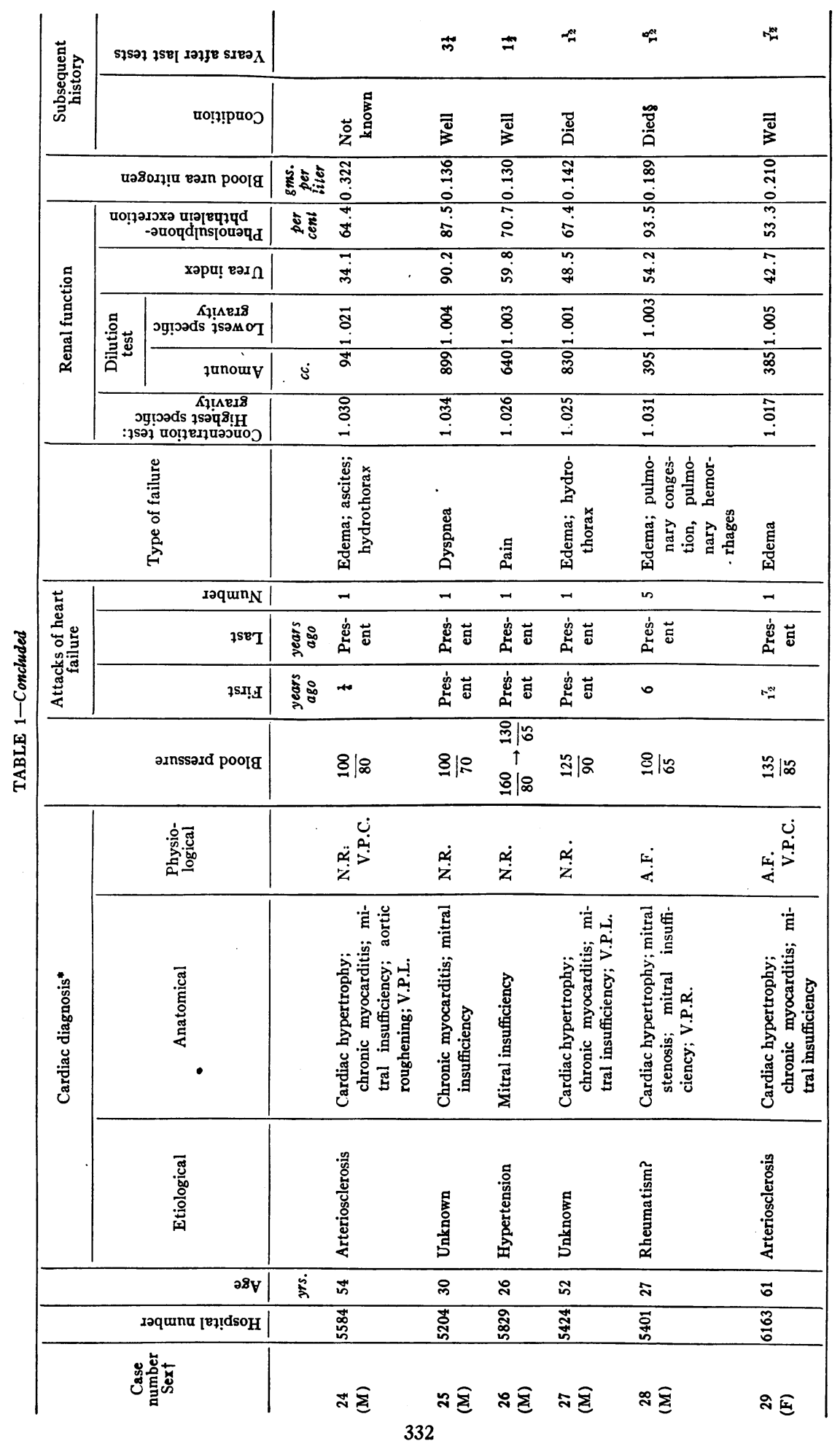




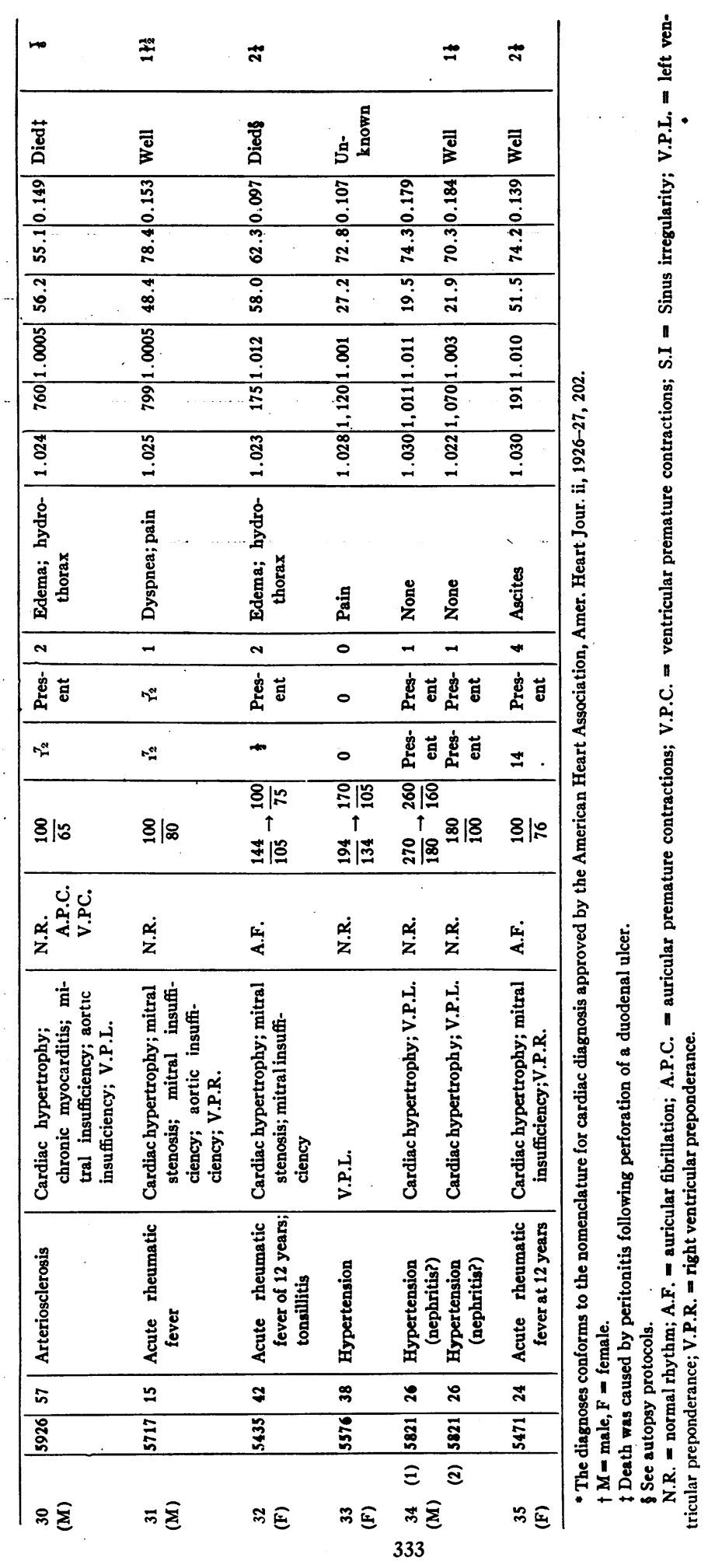


TABLE 2

A summary of results of tests of renal function in cardiac patients

\begin{tabular}{|c|c|c|c|c|c|c|c|c|c|c|}
\hline \multicolumn{2}{|c|}{ Van Slyke index } & \multicolumn{3}{|c|}{ Concentration test } & \multicolumn{3}{|c|}{ Dilution test } & \multicolumn{3}{|c|}{$\begin{array}{c}\text { Phenolsulphonephthalein } \\
\text { test }\end{array}$} \\
\hline Low & Normal & Low & Normal & No data & Low & Normal & $\begin{array}{c}\text { No } \\
\text { data }\end{array}$ & Low & $\begin{array}{l}\text { Nor- } \\
\text { mal }\end{array}$ & $\begin{array}{l}\text { No } \\
\text { data }\end{array}$ \\
\hline 7 & 28 & 9 & 22 & 4 & 13 & 18 & 4 & 1 & 33 & 1 \\
\hline
\end{tabular}

phenolsulphonephthalein was normal in all except one (case 10) of 35 patients. The Van Slyke index was normal in 28 patients (41 tests) (tables 1 and 2), and below normal, though in no instance greatly so, in 7 patients ( 9 tests). In 10 patients the kidneys failed to concentrate urine to a specific gravity of 1.026 to 1.030 , though in only one case did it fall below a specific gravity of 1.020 (case $29,1.017$ ). In 17 patients the results first obtained by use of the dilution test were abnormal. In 7 the only abnormality was failure to excrete $750 \mathrm{cc}$. or more of the $1000 \mathrm{cc}$. of water ingested. In 3, although the specific gravity did not fall to 1.005 , a normal amount of water was nevertheless excreted. In the other 8 patients ${ }^{1}$ (that is to say of the 17) the amount excreted was less than $750 \mathrm{cc}$. and beside the specific gravity did not fall to 1.005 . Five of the 17 showed abnormalities in the concentration test as well. In one patient (case 34) after prolonged rest in bed, when the blood pressure fell, there were decreased values except in the concentration and phenolsulphonephthalein tests. After taking a salt free diet for 6 weeks when the blood pressure fell further, the renal function improved, as indicated by the presence of normal dilution although concentration rose only to 1.022 . In this patient, the diagnosis is not certain. $\mathrm{He}$ may have passed through a stage of acute nephritis to which hypertension was secondary and not primary or essential. In 10 of the 35 patients the values at one time were normal in all the tests, while in 25 the function was decreased at some time in one or more of the tests.

\footnotetext{
${ }^{1}$ Several patients during several years fall now in one group and now in another due to change in the renal function even according to the same tests.
} 
Of 4 patients, data are lacking on the concentration and dilution tests. In summary (table 2) then, all the tests were normal in 10 patients; the Van Slyke index was abnormal in 7 patients and normal in 28; the values of the concentration test were low in 9 patients and normal in 22; the dilution test gave abnormal values in 13 patients (in 3 of these, the values for the concentration test were also low) and normal ones in 18. The concentrating and diluting functions of the kidneys are more frequently impaired in chronic circulatory disease than the ability to excrete urea or phenolsulphonephthalein.

Etiology of heart disease and renal function. The patients were divided into 5 groups on the basis of etiology (fig. 1). In the first group are 11 patients (cases $8,11,12,15,17,19,22,28,31,32$, and 35) in whom heart disease followed acute rheumatic fever. The second group consists of 9 patients (cases 1, 2, 5, 7, 13, 23, 26, 33, and 34) in whom there was arterial hypertension. The third group of 11 patients (cases $3,4,6,14,16,18,20,21,24,29$, and 30 ) was arteriosclerotic. In the fourth group are 3 patients (cases 9, 25 and 27) in whom the etiological agent could not be traced. In the fifth group is 1 patient (case 10) in whom hyperthyroidism was followed by a state of hypothyroidism. Impairment of renal function was not as common in the acute rheumatic fever group as in the other groups. Six of the 10 patients exhibiting normal renal function were in this group. All the patients (11) in the arteriosclerotic group exhibited diminished renal function. The renal function of one (case 13) of the patients in the hypertensive group (consisting of 9 patients) was normal, and that of a second (case 5) returned to normal in the course of 3 years.

Type of heart failure and renal function. The patients were classified in 5 types of heart failure on the basis of the signs and symptoms which they exhibited: First, there are 15 patients (cases 3, 4, 7, 8, 11, 14, 20, $21,24,27,28,29,30,32$ and 35) corresponding to the congestive type, characterized by edema, ascites, pleural effusion, pulmonary congestion and swollen liver. In the second group are 8 patients (cases 6, 12, $15,19,22,23,25$ and 31) who complained of dyspnea, but who did not show signs of congestive heart failure. The third group consists of 6 patients (cases 10, 16, 17, 18, 26 and 33) in whom cardiac pain pre-

2 The diagnoses conform to the nomenclature for cardiac diagnosis approved by the American Heart Association. American Heart Journal, 1926-1927, ii, 202. 
dominated. In the fourth group are 3 patients (cases 2, 5 and 9) in whom heart failure manifested itself as fatigue. In the fifth group is one patient (case 1) who complained only of palpitation. No special

FIG. 1. In this figure the renal functions of patients are charted at the age which they were estimated. Each column represents a patient. The ordinates represent years of age. Symbols indicate renal function, and the etiology of the cardiac disease. The years in which infections occurred, cardiac lesions were diagnosed, symptoms first appeared and attacks of heart failure occurred are also indicated.
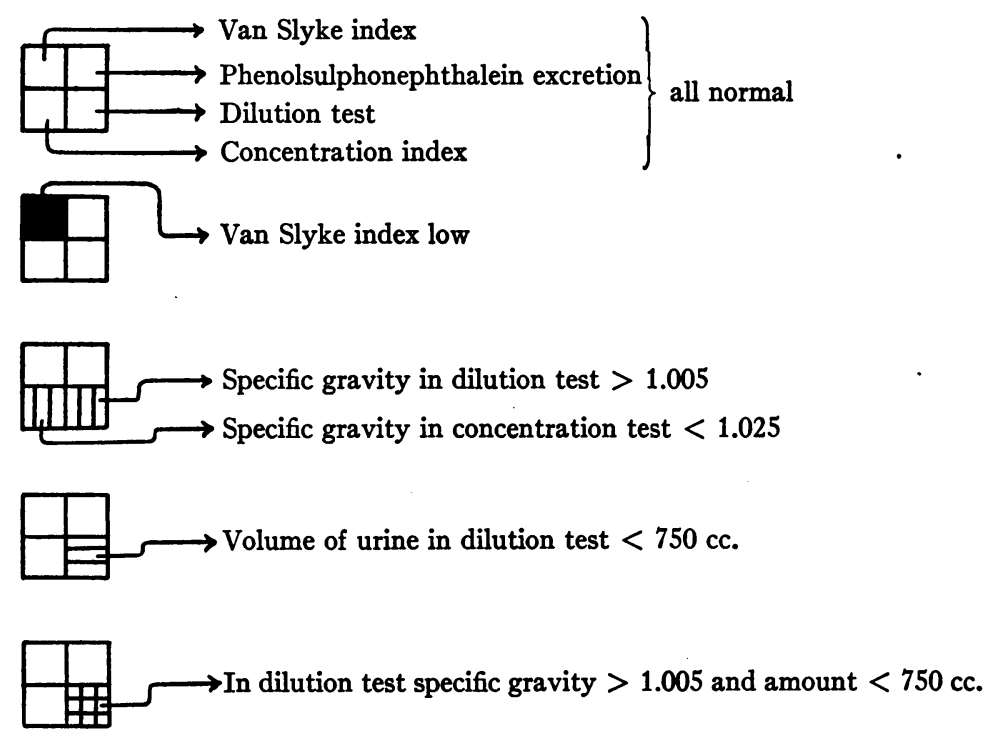

- = Attack of acute rheumatic fever.

$+=$ Attack of chorea.

$\leftarrow=$ Occurrence of symptoms or of cardiac failure.

\# = Cardiac lesion diagnosed.

$\square=$ Etiology is acute rheumatic fever.

- = Etiology is unknown.

$\Delta=$ Etiology is hypertension.

$\Delta=$ Etiology is arteriosclerosis.

$\mathrm{O}=$ Etiology is hypothyroidism.

complaints were to be elicited from 2 patients (cases 13 and 34) who were the subjects of hypertension. Many of the impairments in renal function were discovered in the patients subject to attacks of con- 
gestive heart failure. In this group, the Van Slyke index and phenolsulphonephthalein excretion were normal; all except 2 showed impairment however either in the concentrating or diluting function of the kidneys or in both. But in half the dyspneic group the renal function

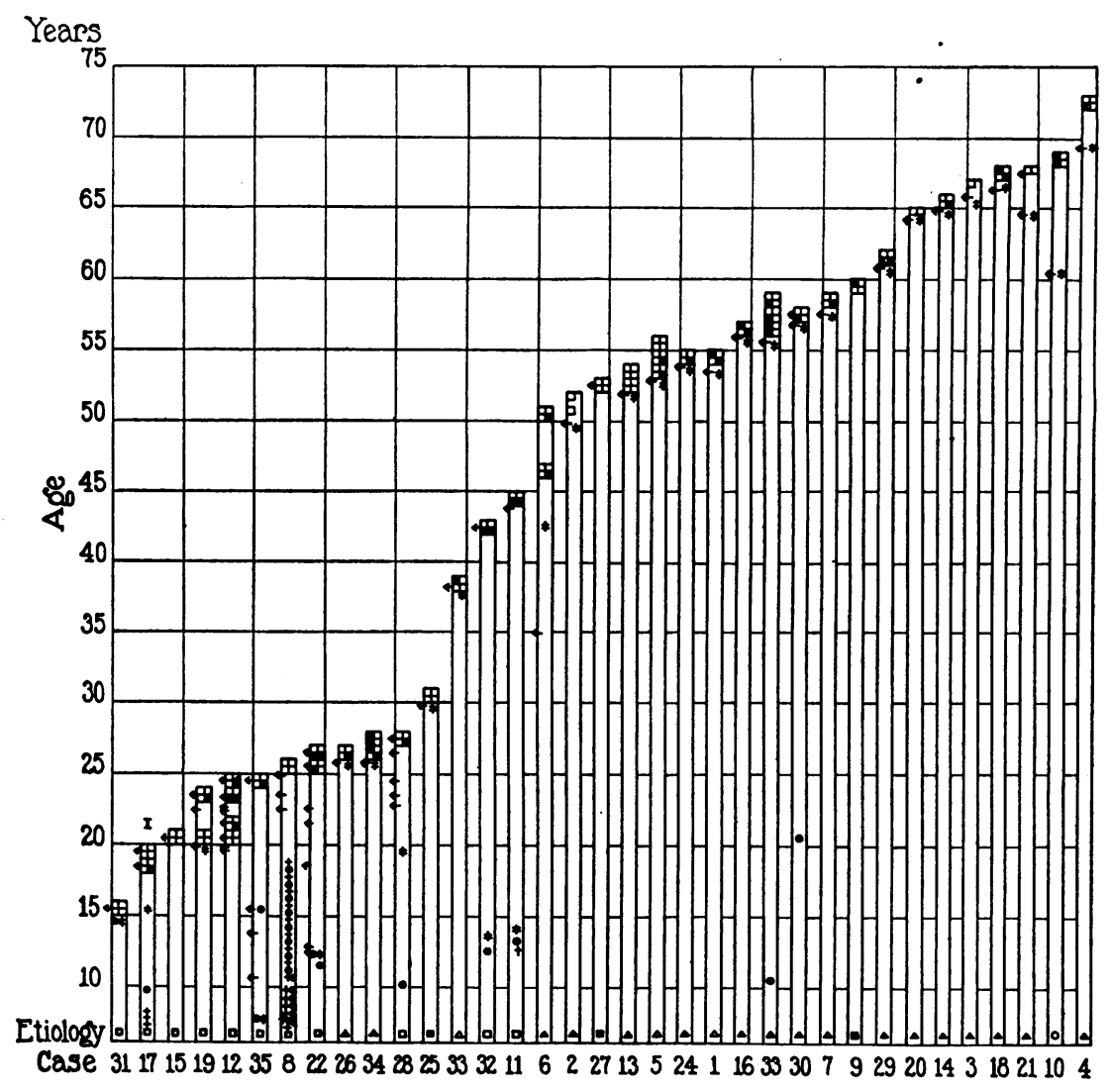

FIG. 1

was normal at one time or another, while in the pain and the fatigue groups one was normal in each.

Relation between duration of the cardiac affection (number of years since first attack of heart failure) and renal function. This interval, since the occurrence of the first attack of heart failure, ranged from $18 \frac{1}{2}$ 
years to one month in 35 patients. Impairment of function did not appear to vary with the duration of the disease, whether months or years. Impairments occurred about as frequently in those who had had only one, as in those who had had repeated attacks. The degree of impairment in short did not parallel the number of attacks of heart failure (see discussion). Nor did there appear to be an outspoken relation between the duration of heart disease ${ }^{3}$ and the degree of impairment, so far as the concentrating and diluting functions of the kidneys are concerned.

Correlation of age and renal function in patients with heart disease. There are 50 observations in 38 patients (Figure 1). Twelve (cases $8,12,15,17,19,22,25,26,28,31,34$, and 35 ) range in age between 15 and 30 years. In seven (cases $8,12,15,17,19,28$ and 31) of these, or about 60 per cent, the function appeared normal in all the tests. But in 23 patients ranging in age between 38 and 72 years, this was true in 3 only (cases 5,13 and 27). Although the number of cases is too few for statistical statement, impairments in renal function are certainly more frequent in heart patients in the decades after 30 years.

Blood urea in heart disease. The blood urea was below 0.200 gram per liter in all except 3 patients.

\section{DISCUSSION}

We have found, on the whole, little impairment in those renal functions which we have been able to measure in patients suffering from chronic heart disease. The number studied is of course small for statistical treatment. The Van Slyke index was abnormal in only 8 patients and phenolsulphonephthalein excretion was diminished in only one. The most frequent impairment was the diluting ability of the kidneys; the concentrating function was second. This was the situation during the stage of compensation. Little or no permanent damage to the kidneys need become established for many years. During the stage of congestion renal function as measured by the Van Slyke index, the phenolsulphonephthalein excretion, and the Mosenthal test diet, is however greatly diminished. Afterwards some impairment becomes evident

${ }^{3}$ The duration of heart disease dates from the time when a diagnosis of heart disease was made; it need not of course coincide with the date of the first attack of heart failure. 
either in the ability to excrete urine of high specific gravity or in the diluting function or in both. It appears then that although the renal function may be normal in the presence of heart disease of long duration, it may be impaired comparatively early. We are not able to ascertain from the observations we have made whether impairment in function is due to damage of an anatomical nature to the renal cells, or whether it is secondary to the physiological conditions under which the cells are functioning, such as those of diminished flow of blood through the renal vessels. That the lesions of which malfunction is the expression are not necessarily permanent is shown by the fact that improvement of renal function occurred in several patients over a period of several years (cases 5 and 23). There are autopsy reports of three patients (cases 12, 19 and 28, (autopsy reports)), in whom the renal function indicated the presence of damage to renal tissue. In none of these cases were lesions of the kidneys characteristic of Bright's disease observed; they were rather those of chronic passive congestion and of healed infarct (autopsy reports). It may be recalled that these three patients were young men in whom the cardiac disease was of rheumatic origin. The other histological data which are available concern older patients in whom vascular lesions were present (cases 3, 20 and 21). On histological examination the renal vessels were arteriosclerotic. In these patients the Van Slyke index and the phenolsulphonephthalein excretion were normal; data are lacking on the dilution and concentration tests. The histological data then which we have at hand are too few to attempt a correlation of specific anatomical lesion with special deviation of renal function from the normal. So far as our observations permit statements to be made, we may say that in younger people no lesions were found characteristic of chronic renal disease even when functional changes (concentration and dilution tests) were detected. In older people arteriosclerotic lesions were present but no change in those tests which were attempted (index of urea excretion and phenolsulphonephthalein test).

It was not possible to establish a relation between the number of attacks of heart failure and the degree of renal impairment. But in three patients progressive change in renal function took place with each attack of heart failure. They were young men, all suffered from the dyspneic type of heart failure; the lesion in each case was mitral steno- 
sis and insufficiency of rheumatic origin. In the first (case 12) all the tests for renal function were normal after recovery from a third attack of heart failure. One year later, after recovery from a fourth attack, he was no longer able to excrete urine of low specific gravity. The amount also descreased as was seen in the dilution test. After the eighth attack two years later, both functions, concentrating as well as diluting, were abnormal. While damage to the heart was progressing continuously change in kidney function also occurred. The general condition and the behavior of the kidneys took a parallel downward course. The second patient (case 19) likewise exhibited normal renal functions after recovery from a first attack of heart failure. Three years later, after the third attack, he could no longer excrete the normal amount of water in the dilution test, nor could he lower the specific gravity to 1.005. His capacity for exertion had meanwhile diminished. The third patient (case 22) had suffered from heart disease for 14 years and had suffered from 6 attacks of heart failure when the first observations were made. These revealed abnormality in the concentration test. One year later, after the seventh attack, the dilution as well as the concentration test was abnormal. During this time he failed rapidly.

Three patients (cases 5, 17, and 23, fig. 1) showed progressive improvement in renal function over a period of several years; clinical improvement occurred at the same time. A fourth patient (case 6) remained unchanged over a period of 5 years, both from the point of view of the clinical course and of the kidneys.

Our observations as we have said, include however neither a sufficiently large number of patients nor do they cover sufficiently long periods to warrant our drawing conclusions on the meaning of the tests we have used from the point of view of prognosis. The situation is in fact confusing. Some patients are alive and are carrying on work without signs of heart failure, though their renal functions are as greatly diminished as were those in others shortly before death.

Deterioration in the renal functions was most common in the arteriosclerotic and hypertensive groups in which they were normal in only two individuals (cases 5 and 13); less common in the acute rheumatic group in which were most of the patients with normal function. Beyond the age of 30 normal function was present in only three (cases 5,13 and 27). The lower age may be 40 or 50 years if larger numbers 
of patients were systematically studied. From these observations it appears however that the kidneys of younger patients with heart disease react differently from those of older ones at least to the tests which were employed. In any cases these are the decades in which senescent involutions are to be expected. It would naturally be important to separate the changes due to the natural aging process from those secondary to chronic circulatory disease. At any rate decreased function in cardiac patients of advanced years appears to be associated neither with the number of attacks of heart failure, nor with the length of time heart disease has existed.

No attempt has been made to correlate changes in function of the kidneys with the mechanism of the heart beat, especially auricular fibrillation; with the variety of valvular lesion nor with right or left sided heart failure. The number of cases is too small.

The Van Slyke index is usually normal, as has been said, in patients with heart disease when they have no signs of heart failure, although the dilution and concentration tests may show diminished function. The reverse was the case however in two patients; the dilution and concentration tests gave normal results, while the Van Slyke index was low (table 1, cases 9 and 23).

Since the diluting and concentrating abilities of the kidneys are the ones most frequently limited in chronic cardiac disease, the test for these functions are the ones which are most useful and give most helpful information. The urea concentration index and the phenolsulphonephthalein excretion may be normal, yet there will be considerable limitation in the range of specific gravity of the urine which is excreted.

\section{SUMMARY}

The urea concentration index (Van Slyke index), the phenolsulphonephthalein excretion and the concentration and dilution tests have been studied in 35 patients with chronic circulatory disease when in a compensated state. It was found that:

1. In 10 patients all the tests for renal function gave normal values.

2. The urea concentration index was normal in all except 8 patients.

3. The phenolsulphonephthalein excretion was subnormal in only one patient. 
4. In 17 patients, that is to say in one half the patients studied, the dilution test revealed abnormality either in the ability to excrete the normal amount of water or in the failure of the specific gravity to fall or in both.

5. The concentration test showed impairment in 10 patients.

6. Diminished renal function was found in all except 3 patients who were more than 30 years of age.

7. A correlation exists between arterio-sclerosis and hypertension and decrease in renal function.

8. The impairments of renal function were found more frequently in patients who suffered from congestive heart failure.

9. There was no correlation between duration of heart disease and impairment in renal function.

\section{CONCLUSIONS}

Although the number of patients is too small to make statistical inferences, the following facts emerge from analysis of the data:

1. After 30 years of age, normal renal function is found rarely in patients with cardiac disease.

2. Normal function is rare in patients with circulatory disease of arterio-sclerotic or hypertensive etiology.

2a. Conclusions 1 and 2 are correlated, since arterio-sclerosis and hypertension are diseases of the later decades.

3. Impairments of renal function were found most frequently in patients subject to repeated attacks of congestive heart failure.

4. Although correct in general, conclusion 3 requires modification by the statement that the degree of impairment did not parallel the number of attacks of failure.

4a. During intervals between attacks of heart failure there may be no impairment of renal function.

5. There was no correlation between the duration of heart disease and the degree of impairment.

5a. There was no correlation between the length of time since the onset of the first attack of heart failure and the degree of impairment.

6a. The Van Slyke index of urea excretion and the phenolsulphonephthalein excretion are usually normal. 
6b. The inability of the kidneys to excrete urine of high and low specific gravity is the most frequent impairment found in patients with chronic heart disease.

6c. In patients with chronic heart disease without heart failure the concentration and dilution tests are more likely to detect abnormalities in renal function than are the index of urea excretion and the phenolsulphonephthalein test.

\section{SUMMARY OF AUTOPSY EXAMINATIONS OF CARDIAC PATIENTS}

Case 3. The anatomical diagnosis was: general arteriosclerosis, chronic cardiac valvular disease, cardiac hypertrophy, aneurysm of the abdominal aorta, diffuse hyperplastic sclerosis of the kidneys and pancreas, renal infarction, arteriosclerosis of the kidneys, terminal broncho-pneumonia, brown infiltration of the lungs, venous stasis of the organs. The microscopical diagnosis was: hypertrophy of the muscle fibers of the heart, thickening of the vessels of the kidneys, hyalinization of the glomeruli and renal infarction, brown induration of the lungs, cyanotic atrophy of the liver, advanced atherosclerosis of the aorta with thickening of the intima and calcification.

Case 12. The anatomical diagnosis was: chronic endocarditis, mural thrombi, calcification of the mitral valve, cardiac hypertrophy, serous pericarditis, ascites, edema of the intestines, chronic passive congestion of the lungs, liver, spleen and kidneys, bronchitis, calcification in both lungs, healed infarct in the right kidney, ulcer of the stomach, moderate atheromatosis of the aorta. The microscopical diagnosis was: chronic endocarditis of the mitral valve and left auricle, chronic pericarditis, recent myocarditis of the right auricle, moderate atherosclerosis of the coronary vessels, moderate atheromatosis of the aorta and pulmonary artery, chronic passive congestion of the lungs, edema of the lungs, atelectasis of the right lower lobe, chronic passive congestion of the liver, passive congestion of the spleen, healed infarcts of the kidneys and passive congestion of the kidneys.

Case 19. The anatomical diagnosis was: chronic endocarditis of the left side of the heart, mitral stenosis, cardiac hypertrophy, serous pericarditis, hyperplasia of the lymph nodes of the esophagus and stomach, hypoplasia of the adrenals, chronic passive congestion of the lungs, passive congestion of the spleen and liver, healed renal infarct, moderate atheromatosis of the aorta. The microscopical diagnosis was: chronic endocarditis of the left auricle and of the aortic and mitral valves, chronic passive congestion of the lungs, passive congestion of the liver, spleen, pancreas and brain, passive congestion of the kidneys, lymphatic hyperplasia of the bronchial and mesenteric lymph nodes, hypoplasia of the adrenal cortex, moderate atheromatosis of the intima of the aorta. 
Case 20. The anatomical diagnosis was: calcification of the aortic valves, stenosis of the aortic valves, cardiac hypertrophy, advanced atherosclerosis of the aorta, moderate atheromatosis of the aortic cusp of the mitral valve and of the coronary vessels, arteriosclerosis of the kidneys, infarcts of the kidneys, cyanotic induration of the liver, passive congestion of the spleen and kidneys, ascites, edema of the legs and intestines, serous pericarditis, sero-fibrinous pleurisy of the left pleural cavity, localized pleural effusion in a space between the upper and middle lobes of the right lung, osteoporosis of the sternum. The microscopical diagnosis was: calcification of the aortic valves, chronic endocarditis and pericarditis of the left auricle, atheromatosis of the aortic cusp of the mitral valve, calcifying atherosclerosis of the intima of the thoracic part and of the intima and media of the abdominal part of the aorta, calcifying atherosclerosis of the splenic artery, adhesive pleurisy of the right pleural cavity, purulo-fibrinous pleurisy in the space between the upper and middle lobes of the right lung, chronic passive congestion of the lungs, atrophic induration of the liver, chronic passive congestion of the liver, atherosclerosis and passive congestion of the kidneys, renal infarction, passive congestion of the spleen and adrenal glands.

Case 21. The anatomical diagnosis was: extreme thrombosis and atherosclerosis of the left coronary artery, focal thrombosis and atherosclerosis of the right coronary artery, myocardial degeneration, healed and recent myocardial infarcts, adherent pericardium, fibrous pleurisy, anthracosis, emphysema, general arteriosclerosis, venous stasis of the liver, perisplenitis, perihepatitis, abdominal adhesions, hyperplasia of the spleen, arteriosclerosis of the kidneys, infarcts of the kidneys. The microscopical diagnosis was: healed canalized thrombi and recent thrombosis of the coronary arteries, endocardial thickening, fibrosis and recent infarction of the left ventricle, atherosclerosis of the aorta, cyanotic atrophy of the liver, fibrous thickening of the pleura, anthracosis, perisplenitis, infarction of the kidneys, atherosclerosis of the kidneys.

Case 28. The anatomical diagnosis was: cardiac hypertrophy, chronic cardiac valvular disease (mitral and aortic), pericarditis, broncho-pneumonia, venous stasis of the organs. The microscopical diagnosis was: chronic endocarditis, anemic infarcts of the heart, chronic passive congestion of the liver, passive congestion of the spleen, passive congestion of the kidneys, congestion and edema of the adrenal glands, normal aorta.

Case 32.4 The anatomical diagnosis was: chronic endocarditis, mitral stenosis and aortic stenosis, cardiac hypertrophy and dilatation, sclerosis of the pulmonary artery, atelectasis of the lower and middle lobes of the right lung, healed bilateral apical tuberculosis, chronic passive congestion of the liver, spleen and kidneys, healed infarcts of the spleen and kidneys.

4 This report was obtained from another hospital and was not complete. 


\section{BIBLIOGRAPHY}

Agnew, J. H., Arch. Int. Med., 1914, xiii, 485. Comparative Study of Phenolsulphonephthalein Elimination and the Incoagulable Nitrogen of the Blood in Cardio-Renal Diseases.

Frothingham, C., and Smillie, W. G., Arch. Int. Med., 1914, xiv, 541. The Relation between the Phenolsulphonephthalein Excretion in the Urine and the Non-Protein Nitrogen Content of the Blood in Human Cases.

Grünwald, H. F., Deutsch. Arch. f. klin. Med., 1907, lxxxviii, 133. Beiträge zur functionellen Nierendiagnostik.

Hedinger, M., Schlayer, Deutsch. Arch. f. klin. Med., 1914, cxiv, 120. Utber die Prüfung der Nierentätigkeit durch Probemahlzeit.

Koranyi, A., Kövesi, G., and Roth-Schulz, W., Leipzig, 1904. Georg Thieme. Pathologie und Therapie der Niereninsuffizienz bei Nephritiden.

Kövesi, G., Roth-Schulz, W., Berl. klin. Wchnschr., 1900, xxxvii, 321. Ueber Störungen der Wassersecernirenden Thätigkeit diffus erkrankter Nieren.

McIntosh, J. F., and Reimann, H. A., J. Clin. Invest., 1926, iii, 123. Kidney Function in Pneumonia.

McLean, F. C., J. Exp. Med., 1915, xxii, 366. The Numerical Laws Governing the Rate of Excretion of Urea and Chlorides in Man. II. The Influence of Pathological Conditions and of Drugs on Excretion.

Mosenthal, H. O., Arch. Int. Med., 1915, xvi, 733. Renal Function as Measured by the Elimination of Fluids, Salt and Nitrogen, and the Specific Gravity of the Urine.

Rowntree, L. G., and Geraghty, J. T., Arch. Int. Med., 1912, ix, 284. The Phthalein Test.

Rowntree, L. G., Fitz, R., and Geraghty, J. T., Arch. Int. Med., 1913, xi, 121. The Effects of Experimental Chronic Passive Congestion on Renal Function.

Rowntree, L. G., and Fitz, R., Arch. Int. Med., 1913, xi, 258. Studies of Renal Function in Renal, Cardio-Renal and Cardiac Diseases.

Rowntree, L. G., Marshall, E. K., Jr., and Baetjer, W., Arch. Int. Med., 1915, xv 543. Further Studies of Renal Function in Renal, Cardio-Renal and Cardiac Diseases.

Strauss, H., Ztschr. f. klin. Med., 1902, xlvii, 337. Die Harnkryoskopie in der Diagnostik doppelseitiger Nierenerkrankungen.

Van Slyke, D. D., Linder, G. C., Hiller, A., Leiter, L., and McIntosh, J. F., J. Clin. Invest., 1926, ii, 255. The Excretion of Ammonia and Titratable Acid in Nephritis.

Volhard, F., Verhandl. Deutsch. Kong. f. inn. Med., 1910, xxvii, 735. Utber die functionelle Unterscheidung der Schrumpfnieren. 